\title{
FAMÍLIAS DE CRIANÇAS QUE NECESSITAM DE CUIDADOS ESPECIAIS: O IMPACTO SOBRE A VIDA FAMILIAR
}

\author{
FAMILIES OF CHILDREN THAT DEMAND SPECIAL CARE: THE IMPACT ON FAMILY LIFE \\ FAMILIAS DE NIÑOS QUE NECESITAN CUIDADOS ESPECIALES: EL IMPACTO \\ SOBRE LA VIDA FAMILIA
}

\author{
Coleta Rinaldi Althoff* \\ Lauri Iva Renck**
}

Salete Virgínia S. S. Sakae***

\footnotetext{
* Membro do Grupo de Assistência, pesquisa e Educação na área de Saúde da Família - GAPEFAM-Pen/UFSC. Doutora em Enfermagem.

** Enfermeira do Hospital Infantil Joana de Gusmão. Mestre em Enfermagem.

*** Enfermeira do Hospital Universitário da Universidade Federal de Santa Catarina. Mestre em Enfermagem.
}

RESUMO. Trata-se de um estudo de natureza qualitativa com o objetivo de identificar o impacto que os problemas de saúde das crianças que necessitam de cuidados especiais têm sobre as famílias. Foram realizadas entrevistas com 16 famílias, das quais oito tinham crianças portadoras de diabetes mellitus e 8 de crianças acometidas por queimaduras. A análise comparativa dos dados revelou que as famílias, ao enfrentarem a situação, reconstroem o modo de viver e se tornam agentes na demanda do cuidado. As famílias manifestam angústia, tristeza, culpa, raiva, medo e expressam preocupação com os cuidados e as conseqüências com o agravamento do problema. Isto implica alterar as rotinas familiares e exercer cuidados especiais com controle e vigilância, aumentando as responsabilidades. As relações familiares se modificam, sendo necessário ajuste nas formas de se relacionar e desenvolver as ações. As famílias procuram se adaptar à nova situação reestruturando valores, alterando papéis e rotinas familiares.

PALAVRAS-CHAVE: família; criança; cuidados especiais; portadores de necessidades especiais.

ABSTRACT. This is a qualitative study and with to identify the impact that special care demands on families by children health problems. This research was based on 16 families who were interviewed, eight of them with children who had diabetes mellitus and 8 with children who had suffered burns. The comparative analysis of the data revealed that due the children's situation families have rebuild their way of living and have become agents in providing them care. The families reveal anguish, sadness, blame, rage, fear and express concern regarding the care and the consequences as the problems get aggravated. This entails consequences such as altering family routines and providing special care which demand close supervision and surveillance, increasing the families' responsibilities. Family relationships become modified and it becomes necessary to adjust how to relate with each other. Families try to adapt themselves to the new situation by restructuring values, and altering roles and family routines.

KEYWORDS: family; child; special care; disable persons.

RESUMEN. Se trata de un estudio de naturaleza cualitativa con el objetivo de identificar el impacto que tienen sobre las familias los problemas de salud de los niños que necesitan cuidados especiales. Se realizaron entrevistas con 16 familias, de las cuales 8 tienen niños portadores de diabetes mellitus y 8 , niños que sufrieron quemaduras. El análisis comparativo de los datos reveló que las familias, al enfrentar la situación, reconstruyen el modo de vivir y se vuelven agentes en la demanda del cuidado. Las familias manifiestan angustia, tristeza, culpa, rabia, miedo y expresan una preocupación con los cuidados y las consecuencias del agravamiento del problema. Ello implica alterar las rutinas familiares y tomar cuidados especiales con el control y la vigilancia, aumentando las responsabilidades. Las relaciones familiares se modifican, lo que hace necesario un ajuste en las formas de relacionarse y llevar adelante las acciones. Las familias se preocupan en adaptarse a la nueva situación reestructurando valores, alterando papeles y rutinas familiares.

PALABRAS-CLAVE: familia; niño; cuidado especial; personas con discapacidad.

Recebido em: 04/03/2005

Aceito em: 16/08/2005
Coleta Rinaldi Althoff

Universidade Federal de Santa Catarina

Centro de Ciências da Saúde, Depto de Enfermagem

Campus Universitário s,n. - Trindade

88040-900 - Florianópolis - SC

Cx. Postal 476 - E-mail: corinaldi@floripa.com.br 


\section{INTRODUÇÃO}

A saúde é um bem desejado pelos seres humanos durante todo o percurso da vida. Nessa trajetória, todos estão sujeitos ao acometimento de problemas de saúde e, quando isso acontece, há um envolvimento na busca de soluções. É na família que isso tem início e suas responsabilidades com os cuidados dos membros estão presentes ao longo da vida. Quando falamos de família, identificamo-la como grupo social complexo e multidimensional, com estruturas, papéis, funções, crenças e poderes próprios e interligados ao ambiente em que vive. A família é unidade significativa e alicerce na vida das pessoas. Nas últimas décadas, os profissionais de diferentes áreas do conhecimento Ihe têm direcionado o foco de atenção, tanto no desenvolvimento de estudos, quanto na aplicação de conhecimentos. Neste sentido, o nosso interesse está em ampliar o conhecimento sobre o viver da família no enfrentamento do processo saúde-doença a que a criança está sujeita. Entre os vários problemas de saúde, nossa direção está voltada para aqueles que se referem à condição de comprometimento da integridade, como as queimaduras, e os que indicam o acometimento das doenças crônicas, como a diabetes mellitus.

A diabetes mellitus é uma doença endócrina, que tem comprometimento importante no metabolismo dos carboidratos. A criança diabética necessita de atenção contínua, diária que, por sua natureza, se torna especial. Ao estudar famílias que convivem com crianças portadoras de diabetes, identificaram-se os cuidados indispensáveis para o controle da condição e os fatores envolvidos na construção deste processo ${ }^{1}$. Ao desempenhar a função cuidadora específica para o controle da diabete, a família se depara com a necessidade de construir cuidados, antes alheios ao seu contexto, e que os significados das dificuldades e dos cuidados vão sendo modificados, à medida que convive com a doença ${ }^{1}$.

A queimadura, por sua vez, é uma injúria decorrente de um acidente pela exposição ao calor extremo. As crianças com lesões graves são submetidas a um tratamento prolongado e doloroso.
A situação de queimadura na criança provoca alterações na vida familiar desde o momento da ocorrência do acidente até o retorno para casa ${ }^{2}$. As reações dos membros da família podem influenciar no tratamento e recuperação da criança.

A família, na sua vida diária, desenvolve uma dinâmica própria para atender às necessidades de seus integrantes. Contudo, quando a família se encontra em face de evento crítico relacionado ao problema de saúde de um dos membros, a vida familiar tende a sofrer alterações com a nova situação. Quando é a criança quem apresenta o problema de saúde, a necessidade de prestar cuidado vai além do comumente realizado e, dependendo do tipo, ele apresenta características especiais. Essa situação acaba envolvendo todos os membros; a vida familiar tende a sofrer modificações; tudo o que os envolve gera experiências significativas para o próprio viver. Neste sentido, estudos realizados com famílias que vivenciam esta situação fazem referência às dificuldades relacionais e limitações que seus integrantes passam, ao viver em função do doente e das suas necessidades constantes ${ }^{1 ; 2 ; 3 ; 4}$. As famílias que se encontram nessa situação, independentemente dos aspectos específicos que as diferenciam, apresentam

"a mesma configuração no que se refere à doença como elemento organizador dos padrões relacionais. A dificuldade de favorecer a saúde emocional se apresenta na medida em que estes sistemas não disponham de recursos internos e/ou externos para fazer face à tensão por tempo prolongado ou por toda a vida" 3:237.

Embora os estudos ainda sejam incipientes, eles apontam as mudanças nos relacionamentos que podem afetar negativamente a interação dos membros das famílias; a dificuldade em aceitar a realidade pode agravar o desenvolvimento da criança. "As evidências apontam que as relações familiares são fundamentais para o adequado enfrentamento da doença e do prolongado tratamento que comumente se faz necessário" 4:633. 
Os cuidados especiais são aqueles que demandam maior esforço e envolvimento dos membros das famílias para atender às necessidades específicas da criança em decorrência da existência do problema de saúde. A família tem a responsabilidade de buscar recursos e exercer as atividades do cuidado. Entretanto ter uma criança com necessidades de cuidados especiais é, muitas vezes, difícil para a família. A maneira como ela interpreta e enfrenta a situação é acompanhada de significados que conduzem ao desenvolvimento das ações. No cenário da prática, quando nos deparamos com as famílias que se encontram em situações críticas, surgem alguns questionamentos e, entre eles, tecemos os seguintes: Qual a percepção da família sobre a situação? Como se organiza para enfrentar as necessidades da criança e dela própria? Qual o impacto que a situação tem sobre a família?

$\mathrm{Na}$ busca de respostas para as questões e partindo da perspectiva de que o enriquecimento científico está na compreensão do outro, na capacidade de reflexionar sobre a realidade, para que possamos dar amplitude ao nosso pensamento e a nossas práticas, desenvolvemos este estudo com o objetivo de identificar o impacto que os problemas de saúde das crianças que necessitam de cuidados especiais tem sobre as famílias.

\section{A METODOLOGIA}

Este é um estudo exploratório - descritivo de natureza qualitativa. Após aprovação do projeto pelo Comitê de Ética em Pesquisa da UFSC, deu-se início ao levantamento de dados. Os sujeitos foram constituídos por 16 famílias que freqüentaram o ambulatório de pediatria dos hospitais: Universitário da UFSC e Hospital Infantil Joana de Gusmão, em Florianópolis, SC. Destas famílias, 8 têm crianças portadoras de diabetes mellitus e $8 \mathrm{com}$ crianças acometidas de queimadura, aqui denominadas FD e FQ em numeração seqüencial $(1,2,3,4,5,6,7,8)$.

A partir do agendamento das consultas de enfermagem marcadas pelo serviço de atendimento nos ambulatórios, as famílias foram selecionadas e convidadas a participarem do estudo. Nesse momento foram oferecidas informações a respeito da finalidade e objetivo do estudo e a seguir deu-se a assinatura do termo de consentimento livre e esclarecido pelos membros responsáveis. Foram garantidos o sigilo e a privacidade dos sujeitos além do respeito aos seus valores culturais, morais, religiosos e sociais. Os dados foram obtidos em entrevistas realizadas com os membros das famílias e as crianças presentes no momento da consulta de enfermagem. O número de entrevistas foi estabelecido de acordo com a saturação dos dados identificada na análise qualitativa e o tempo disponível para a realização do estudo. A entrevista constituiu-se de duas partes. A primeira com questões relacionadas à identificação da família; a segunda, com questões relativas ao problema de saúde e o atendimento às necessidades de cuidado especial de criança.

Os procedimentos para o desenvolvimento do processo analítico foram baseados no método de análise comparativa dos dados de Strauss e Corbin ${ }^{5}$. A partir da transcrição integral das fitas e da leitura do material, iniciamos a análise grifando e registrando os termos que sinalizavam a idéia. $A$ seguir, selecionamos o material e agrupamos de acordo com as semelhanças e diferenças dos relatos apresentados pelas famílias entrevistadas. Após a separação dos dados, examinamos com critério as informações obtidas, comparamos e procuramos destacar as idéias relevantes. Esse material foi novamente examinado e codificado. Após a releitura dos códigos, os agrupamos e formamos categorias, dando origem aos temas.

\section{OS RESULTADOS EM EVIDÊNCIA}

A análise dos dados proporcionou 0 agrupamento dos seguintes temas: a reconstrução da realidade da vida em família e a família como agente na demanda do cuidado.

\section{A RECONSTRUÇÃO DA REALIDADE DA VIDA EM FAMÍLIA}

Recordando a questão formulada durante as entrevistas "quem faz parte da família?", verificamos que a idéia de família está relacionada à forma como 
ela se estrutura socialmente e como são estabelecidas as ligações entre seus membros. No nosso mundo social, essas estruturas se apresentam com variação ampla. Ao lado do modelo família nuclear, tradicional, formado pelo pai, mãe e filhos, há a pluralidade e a diversidade de arranjos familiares, entre eles, famílias monoparentais chefiadas por mulheres e famílias agregadas constituídas por avós, mães e filhos. As configurações familiares apresentadas pelas famílias de nosso estudo não fogem aos padrões referidos. $A$ consangüinidade, a afetividade e o fato de morar junto constituem elementos importantes no momento de distinguir quem faz parte da família. Entretanto algumas pessoas declaram que o genro, o marido do primeiro casamento ou o pai da criança, que não vive junto, pode ser ou não considerado membro da família. Isso depende da ligação estabelecida entre eles ou da participação desse indivíduo na questão financeira do grupo familiar. Desse modo, neste estudo, a família é lembrada como grupo social formado por membros presentes no dia-a-dia ou que estabelecem ligações afetivas ou de compromisso. Esta idéia de família é encontrada em outras investigações ${ }^{1 ; 2}$; contudo as famílias deste estudo expressam com ênfase estes elementos. Acreditamos que isso se deva à necessidade de maior participação dos membros nas ações que a vida cotidiana exige, em face da situação em que se encontram no momento.

Quando as famílias foram abordadas para falarem sobre a vida familiar, elas apontaram alguns aspectos interessantes. $\mathrm{O}$ ato de pensar sobre o momento vivido as faz refletir sobre os valores, as relações estabelecidas entre seus membros e com os outros e sobre a capacidade de organização e estruturação para atender às demandas da vida cotidiana. Esse despertar para a reflexão fez surgir expressões como esta: (...) coisinhas mais simples da vida, coisas a que não dava valor (FQ4). Entendemos que a situação vivida delineia a reconstrução do modo de viver das famílias. Elas revelaram aspectos particulares em relação aos sentimentos e comportamentos. Para algumas, a experiência de viver a situação possibilitou o fortalecimento dos vínculos familiares: nossa família até melhorou um pouco (...) uniu um pouquinho mais (FD2), enquanto, para outras, as mudanças nos relacionamentos com a própria criança e com os demais membros são percebidas sob outra perspectiva. Uma das famílias declarou: interfere porque por mais que a gente queira que seja uma criança normal, tenha o mesmo direito que o irmão (...) no interior, no coração, aqui no fundo, há uma diferenciação (FD4). Contudo, em ambas as situações, diabetes e queimadura, constamos que as famílias identificaram um fator positivo advindo da condição vivenciada: a união dos membros da família e a valorização da vida. Elas lembraram que a situação pode, algumas vezes, estimular comportamentos que favoreçam o bem-estar familiar, como se percebe na seguinte declaração: eu e o meu marido estamos bem agora, ele endireitou, me trata bem, está trabalhando (FQ1).

Dentre os desdobramentos revelados pelas famílias em sua convivência com o problema de saúde, identificamos os sentimentos relacionados ao sofrimento. Estes sentimentos, muitas vezes, foram expressos com comoção penosa, presença de lágrimas e soluços, voz entrecortada, entre outros sinais corporais que denotavam sua forte carga emotiva. As famílias utilizaram vocábulos que buscavam definir sua aflição em face do acontecimento. Em relação à doença elas manifestaram angústia, desespero, culpa, raiva, medo, tristeza e preocupação.

A culpa e o medo configuraram reações com características diferenciadas. A culpa, nas famílias que convivem com crianças portadoras de diabetes apresentam aspectos relativos à causa, predominantemente na forma interrogativa: por que aconteceu? Por que ela pegou e não o irmão que tem os mesmos cuidados? (FD4) Já nas famílias que convivem com crianças que sofreram queimaduras a culpa apareceu de forma veemente acompanhada de intenso sofrimento, justificada pela negligência e falta de medidas de prevenção no próprio ambiente de vida da família. Uma mãe traduziu esta situação expressando: me culpei, me achei uma mãe horrível 
(FQ3). Outra família, cuja criança sofreu queimadura grave relatou: a gente não fala sobre o assunto na família. Não adianta a gente ficar lembrando (...) para não causar sofrimento. Mas, lá no fundo a gente acha que não cuidou bem, ela já poderia estar bem grande, caminhando, falando. Mas a gente não conversa sobre isto (FQ1). O sofrimento é algo que permeia todas as famílias, gerando comportamentos diferenciados no aparecimento do problema, no curso progressivo da situação e no momento atual da vivência. O momento inicial é de desespero, indignação, retratado nas palavras de um pai: eu fiquei bastante revoltado (FD1). Por que com ela? Por que eu tenho que passar por isso? (FD7). Com o passar do tempo, as pessoas vão se ajustando à nova realidade; porém a conformação com a situação ainda é difícil. Uma família observou: estou mais acostumada com a situação, mas aceitar... (FD3).

As famílias também manifestaram preocupações com as conseqüências dos distúrbios vivenciados pela criança. Aquelas que convivem com crianças portadoras de diabetes mellitus expressaram preocupação com os descontroles glicêmicos (hipo e hiperglicemia) e também com as possibilidades de complicações crônicas que podem ser geradas pela doença. As famílias que convivem com crianças que sofreram queimaduras expressaram preocupação com o aspecto físico da criança relacionado à presença das cicatrizes. Enquanto a preocupação das famílias estava centralizada na alteração das condições de saúde da criança, pouca atenção era dada às relações entre o casal. Essa questão pode ser observada no seguinte depoimento: a gente, às vezes, até fala que está faltando desejo. Mas não é verdade, é simplesmente porque a gente se preocupa (...) a crise (...) a gente fica com tanto medo que coloca ela no quarto da gente (...) e isso interfere na nossa intimidade (FD4).

Em relação ao aspecto financeiro, tanto para as famílias de crianças com diabetes quanto para às crianças com queimaduras, a situação é acompanhada pela dificuldade de assumir mais este encargo. Na situação de queimadura na criança, as mães que trabalhavam fora de casa tiveram que sair e se dedicar aos cuidados em tempo integral. Esse comportamento leva à diminuição da renda familiar, justamente no momento em que a família tem um aumento das despesas. Isto traz um transtorno para a vida em família. É geralmente a mãe que abre mão de desenvolver suas atividades fora do lar e se volta para o desenvolvimento das tarefas domésticas e o cuidado à criança.

As famílias do estudo, ao discorrerem sobre os problemas de saúde que acometeram seus membros afirmam que, antes do surgimento da situação, elas tinham pouca ou nenhuma informação sobre como lidar com o problema. Elas só tomaram conhecimento ao buscarem os recursos institucionais. Uma das famílias afirma: na época foi um choque, a gente nem imaginava como lidar com ela, aí nós viemos para cá, foram instruindo a gente (...) o que a gente conhece, a gente aprendeu aqui (FD5). A outra declara: o tratamento que eu faria em casa (queimadura) é aquele bem ultrapassado, falaram que nada disto se faz (FQ3). No tratamento das queimaduras as famílias não imaginavam que o tratamento fosse longo e complicado. Uma mãe afirma: é muito sofrido para a criança e para a família. Deixa a marca para o resto da vida (FQ5). O impacto do problema de saúde da criança sobre a família pode gerar tensão entre seus membros e transtornos para a vida cotidiana, observadas nas declarações: ficou mais difícil, a gente se preocupa mais (FD6); alterou tudo e mais um pouco (FQ6).

Observamos, neste estudo, que as famílias, ao detectarem o problema de saúde e ao perceberem que não tinham competências para encontrar uma solução, elas se dirigiam às instituições de saúde na busca de tratamento, mas resistiam em pedir ajuda a seus familiares e vizinhos. As famílias de crianças portadoras de diabetes referiam que essa era uma situação de família. Isso parece indicar que o problema deveria ser resolvido dentro dos limites de seu mundo familiar. Quanto às famílias das crianças acometidas de queimaduras, elas pareciam sentir o peso do descuido e evitavam a exposição ao 
meio social para não dar explicações sobre o ocorrido. Somente a falta de recursos financeiros para o tratamento as fazia se sentirem obrigadas a pedir ajuda. Somadas a estas preocupações as famílias das crianças com queimaduras mencionaram o desconforto com a opinião das pessoas: Quando eu saio, às vezes, me sinto ruim, porque as pessoas olham, perguntam e eu fico quieta, às vezes não respondo, outras vezes, quando eu fico nervosa, eu respondo que eu não preciso dar explicação (FQ1). Outra questão importante a ser destacada é a relativa aos aspectos legais relacionados à responsabilidade do cuidado da criança. Esses aspectos, quando aplicados a algumas famílias visitadas pelo conselho tutelar ou que necessitaram comparecer à delegacia para dar esclarecimentos sobre a ocorrência trouxeram conseqüências para a vida familiar. Como estavam sob investigação, suas ações eram controladas socialmente, dificultando ainda mais as atividades de trabalho e, conseqüentemente, o rendimento familiar

A situação vivida pelas famílias impõe mudanças na vida familiar, em função do foco de atenção ser a criança e o tratamento. As famílias precisam adaptarse à nova situação e a se organizarem para atender as necessidades da realidade.

\section{A FAMÍLIA COMO AGENTE NA DEMANDA DE CUIDADO}

Em decorrência da situação presente na vida das famílias, estas procuram estruturar as suas vidas de modo que a atenção seja direcionada ao membro que necessita de cuidados. Isto implica mudar a rotina familiar existente e exercer cuidados especiais, aumentando as responsabilidades. Embora em ambas as situações, queimadura e diabetes, seja requerida das famílias a modificação do modo de viver, elas se dão por diferentes questões.

$\mathrm{Na}$ situação de diabetes os aspectos relacionados à alimentação, ao sono e ao lazer, têm comprometido a vida cotidiana das famílias. A alimentação tem forte impacto na vida familiar. Em função de a criança necessitar de dieta especial, a família toda incorpora novos hábitos alimentares; portanto altera os hábitos como as atividades relacionadas a ela, como a do lazer da família, observado na seguinte declaração: $A$ gente não sai mais como antes (...). ia comer uma pizza (...) e hoje mudou (...) a gente está procurando mais se adaptar à alimentação dela (FD3). A dieta da criança também muda a rotina da família, no sentido de que está sempre vigilante quanto ao que a criança procura para alimentar-se. O seguinte depoimento retrata a situação: Agora ela está me cutucando, querendo comer bolacha e eu dizendo que não (FD3). Eu tinha que viver vinte e quatro horas cuidando dele, porque até dormindo ele dava um jeito de ir à geladeira (FD5). O sono também é comprometido, uma vez que as famílias temem que a criança tenha episódios de hiperglicemia e/ou hipoglicemia durante a noite. Em algumas situações, a criança dorme junto com os pais: $A$ gente fica com tanto medo, com tanto receio de não dar tempo de chegar no quarto dela, ou qualquer coisa assim que a gente a coloca no quarto da gente (FD4). Percebe-se, nesta situação, a constante preocupação com o que pode acontecer à criança, pois a qualquer momento a doença, quando não controlada, pode exacerbar-se. Pela mesma justificativa, o lazer também é prejudicado. Ele não pode passar férias na casa de ninguém (...) que eu não deixo ele sair sozinho para jogar bola com os amigos dele (FD5), declarou a família.

$\mathrm{Na}$ situação de queimadura, os cuidados especiais com o tratamento, a imagem corporal da criança e o alerta para as medidas de prevenção são as novas preocupações das famílias. A atenção com a pele recém epitelizada é um dos cuidados especiais. O uso do sabonete especial, o cuidado para a criança não se machucar, tomar sol e brincar, são algumas das ações realizadas pelas famílias, para que o resultado do tratamento favoreça a recuperação. Isto leva ao controle ou à vigilância constante. A imagem corporal da criança é uma construção individual e social muito importante para aqueles que vivem a situação. Tenho a preocupação 
da cicatriz na perna dela, porque é uma menina e a gente sempre gosta de vestir um shortinho (FQ5), declarou a mãe. Percebe-se que a alteração da imagem corporal proveniente da queimadura afeta todos os membros da família. Muitas vezes, a criança e a família necessitam reelaborar as imagens corporais, levando em consideração os sinais advindos da lesão. Surgem momentos conflituosos, sentimentos de vergonha, incapacidade e culpa dependendo da maneira como elas consideram a situação. Muitas vezes, isto pode influenciar as interações sociais, pois as crianças são observadas com curiosidade, como se fossem imagens bizarras, uma vez que a sociedade valoriza o belo e o perfeito. Em decorrência da queimadura, as famílias ficam mais atentas e buscam desenvolver medidas de prevenção no ambiente doméstico. Não deixo nada perto dela, não a deixo chegar perto de nada, não a deixo e nem os outros filhos na cozinha (FQ5), declarou a família.

É importante destacar que em ambas as situações, os cuidados especiais são assumidos essencialmente pelas mulheres: mães, avós e irmãs. Eventualmente, os homens ajudam nessa função. Quase sempre sou eu, meu marido só me ajuda nos finais de semana ou à noite, porque ele trabalha o dia todo e, às vezes, a minha irmã e a minha mãe (FQ1).

\section{REFLETINDO SOBRE OS ACHADOS}

Os resultados deste estudo indicam que a condição de saúde da criança acometida pelo diabetes ou pela gravidade e tratamento prolongado da queimadura, interfere no cotidiano da vida familiar, provocando impacto sobre o viver das famílias. Desde o momento inicial, quando o problema de saúde as surpreende e as submete ao enfrentamento da nova realidade, os sentimentos, as preocupações e o envolvimento com as novas atividades de cuidado atingem todos os membros.

As reações emocionais são muito intensas. Ao mesmo tempo que as famílias percebem a união dos membros como força para enfrentar a situação, ter uma criança nesta situação traz muito sofrimento.
A idéia de que a causa, direta ou indireta, esteja ligada aos pais, gera a culpa e, muitas vezes, surge como o elemento desagregador das relações familiares. É comum se sentir culpado ou colocar a culpa no outro provocando conflitos entre eles. A vida familiar parece desestabilizar-se. As relações familiares se tornam mais difíceis e distantes. Porém a literatura revela que não é somente nestas situações que isso acontece. Estudos realizados com famílias que tem filhos com outros tipos de problemas de saúde apresentam resultados semelhantes. Uma vida de dependência relacionada à doença, com desgaste físico e emocional, tanto da criança quanto da família, é identificada nas famílias com filhos portadores de fibrose cística ${ }^{6: 66}$. Em famílias de autistas e portadores da síndrome de Down, o nível de tensão grande e prolongado pode destruir a capacidade de funcionamento da família ${ }^{3}$. As reações das famílias a uma doença crônica ou incapacitante podem ser caracterizadas pelo choque, descrença, negação, culpa, rejeição e raiva ${ }^{7}$. Contudo observamos que os sentimentos inicialmente negativos evoluem para a forma positiva com a esperança e a confiança obtidas com o apoio e o suporte profissional e social.

A preocupação com a criança é uma constante na vida das famílias. Elas sofrem com a situação e reconhecem que é preciso dedicação. As situações ansiogênicas estão vinculadas tanto aos problemas de saúde quanto à demanda de cuidados, exigindo mais atenção e comprometimento. Neste sentido, a informação é determinante na modificação de atitudes e desenvolvimento de habilidades. As famílias obtêm as informações específicas com os profissionais durante a internação ou no atendimento ambulatorial. Entretanto, na convivência diária com a doença, as famílias adquirem conhecimento sobre a situação da criança e desenvolvem uma visão mais aguçada em relação aos aspectos clínicos e emocionais, passando a conhecer as suas reações e necessidades ${ }^{6}$. As situações exigem cuidados especiais. Esta é uma função crucial para as famílias. Isso faz com que o dia-a-dia sofra mudanças, sendo necessários alguns ajustes nas formas de se relacionar e desenvolver as 
ações levando-as a reestruturar os valores, alterar os papéis e as rotinas familiares.

Uma das principais dificuldades enfrentadas pelas famílias da criança com diabetes está na alimentação. O controle alimentar e a reconstrução de hábitos alteram a rotina familiar e os demais membros se sentem afetados pela mudança de hábitos. Quanto à atenção das famílias de crianças com queimaduras, os cuidados exigem a presença constante do cuidador. Desse modo, a vigília e o estar presente levam ao desgaste físico e emocional dos membros das famílias, principalmente daquele responsável pelo cuidado.

As famílias precisam reestruturar-se e também adaptar-se, pois a criança tanto com queimaduras como com diabetes necessita de cuidados especiais. As mulheres, especialmente as mães, são as principais cuidadoras. A mãe abre mão de outras atividades e papéis para atender seu filho, acarretando, com isso, certas dificuldades no relacionamento intra e extrafamiliar ${ }^{6: 72}$. Embora se observe tentativa de mudança nos papéis familiares, o cuidado está relacionado com as tarefas domésticas, até hoje de responsabilidade, predominantemente, feminina. As famílias dão maior ênfase à figura materna uma vez que ela está mais envolvida com o cuidado diário dos filhos, o que a torna mais sensível à doença e seus efeitos ${ }^{8}$. De fato, a mulher tem assumido rotineiramente esse papel. Contudo, no mundo contemporâneo, os papéis sociais estão em transformação e eles precisam ser repensados e distribuídos entre os membros das famílias. É importante que as famílias que têm situação de doença crônica tenham flexibilidade na estrutura familiar, para garantir que todos desempenham seus papeis e assumem outros, quando houver necessidade ${ }^{9}$. Quando um dos membros da família não participa, ele vê a sua parte como desigual, pode sentir-se negligenciado ou criticado; isso pode levar à percepção irreal do tempo e energia gastos na realização das atividades e, conseqüentemente, a conflitos conjugais ${ }^{7}$.
Compartilhar os papéis familiares é ação que possibilita a interação favorável ao bem-viver de todos. É necessária a construção de estratégias de adaptação para enfrentarem a situação, tanto para cuidar da criança com mais confiança, quanto para dar atenção aos outros membros e manter a dinâmica familiar.

Quanto à rede social formada por tios, avós, madrinhas e vizinhos, embora presentes, nem sempre é bem recebida pelas famílias. Elas parecem sentirse diferentes e preocupadas com a discriminação social pelo fato de ter uma criança que exige cuidados especiais de controle e recuperação. Acreditamos que esses comportamentos revelam as dificuldades que as famílias têm ao enfrentar a situação, perante o seu meio social. Têm-se a idéia de que a família se volta para si e se fecha. Isto pode levar ao comprometimento das relações familiares internas e externas. "Cada indivíduo e cada família tem uma forma singular de ser e de enfrentar essa situação, não existe um modelo ideal de funcionamento que

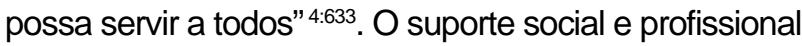
é de fundamental importância para o bem-estar de todos. O conhecimento do problema de saúde e cuidados facilita a interação dos membros com possibilidades de relações harmônicas e ações positivas. É por meio das interações de proximidade das pessoas envolvidas, pela troca de informações e por tomar o papel do outro que o ser humano tem consciência de si, como membro da família ou como profissional em seu papel social.

\section{CONSIDERAÇÕES FINAIS}

As interações sociais que acontecem no mundo das famílias estão relacionadas à maneira como seus membros se estruturam e moldam o que fazem. Com a presença de problemas de saúde nas crianças, a compreensão e a adaptação à nova situação são importantes para as famílias no enfrentamento das dificuldades e no desenvolvimento de habilidades. Isso conduz à maturidade emocional e relacional de seus membros, tornando a convivência familiar mais harmônica. 
O cuidado como função social é prática exercida pelas famílias e ocupa lugar central no atendimento da criança com problema de saúde. Assim, ao assumir o cuidado, a família procura organizar-se, definir atribuições, construir relações e interações dos seus membros para atender às necessidades de seu grupo. Deste modo, as práticas realizadas no cotidiano participam na construção do viver em família com influência sobre o processo de viver da criança e de todos os membros.

A abrangência da vida familiar é ampla e não nos permite, nesse momento, abordá-la na sua totalidade. Este estudo possibilitou um recorte deste universo e o nosso interesse está em ampliar o conhecimento da família, para que possamos utilizar estratégias de intervenção mais eficazes, sensíveis às necessidades de todos, de modo a bem conduzir a situação. As enfermeiras, ao exercerem suas ações de cuidado, podem despertar, nas famílias, as tomadas de consciência da situação, auxiliando-as na compreensão e participação do cuidado.Trabalhar com a família inclui o envolvimento de todos e isso compreende conhecê-la nas ações e interações que desenvolve na sua vida diária, na convivência com seus membros e com a sociedade e nas demais experiências que os eventos da vida proporcionam ao seu viver.

\section{REFERÊNCIAS}

1 Sakae SVSS. A enfermeira e as famílias: construindo um cuidar compartilhado para crianças portadoras de Diabetes mellitus. [dissertação] Florianópolis (SC): Programa de pós-graduação em Enfermagem da Universidade Federal de Santa Catarina; 2004.

2 Renck LI. Enfermagem às famílias das crianças com queimaduras; criando o processo de cuidar na perspectiva interacionista. [dissertação]. Florianópolis (SC): Programa de pós-graduação em Enfermagem da Universidade Federal de Santa Catarina; 2004.

3 Sprovieri MHS, Assumpção Jr FB. Dinâmica familiar de crianças autistas. Arq Neuro-Psiquiatr 2001; 59(2): 230-7.

4 Castro EK, Piccinini CA. Implicações da doença orgânica crônica na infância para as relações familiares: algumas questões teóricas. Psicol Reflex Crit; 2002;15 (3):625-35.

5 Strauss A, Corbin J. Basics of qualitative research: grounded theory procedures and techniques. Thousand Oaks: Sage; 1990.

6 Furtado MCC, Lima RAG. O cotidiano da família com filhos portadores de fibrose cística: subsídios para a enfermagem pediátrica. Rev Lati-Am Enferm 2003; 11(1): 66-73.

7 Wong DL. Enfermagem pediátrica: elementos essenciais à intervenção efetiva. Rio de Janeiro: Revinter; 1999.

8 Zanetti ML, Mendes IAC. Análise das dificuldades relacionadas às atividades diárias de crianças e adolescente com Diabetes Mellitus tipo 1: depoimento das mães. Rev Lati-Am Enferm 2001; 9(6): 25-30.

9 Messa (2004), Messa AA.O impacto da doença crônica na família. Disponível em: http://www.psicologia.org.br/ internacional/psc149.htm. (30 jan 2004). 